\title{
A research into the thermodynamics of methanol to hydrocarbon (MTH): conflictions between simulated product distribution and experimental results
}

\author{
B. Liu ${ }^{1,2} \cdot$ B. Yao $^{2}$ - S. Gonzalez-Cortes ${ }^{2}$ V. L. Kuznetsov ${ }^{2}$ - M. AlKinany ${ }^{3}$. \\ S. A. Aldrees ${ }^{3}$ Tiancun $\mathrm{Xiao}^{2} \cdot$ Peter P. Edwards ${ }^{2}$
}

Received: 27 March 2017 / Accepted: 24 April 2017/Published online: 11 May 2017

(c) The Author(s) 2017. This article is an open access publication

\begin{abstract}
Thermodynamic calculations and analysis were carried out for a rational understanding of the results from selected laboratory MTH reactions. Simulations without solid carbons (coke), $\mathrm{CO}, \mathrm{CO}_{2}$ and light alkanes target on the yield of olefin and aromatic products, which has been found better referenced to the real experimental observations that occur in time-on-stream (TOS). The confliction between simulated data and real experimental results is presumably ascribed to the limited dwelling time of products in the reaction system. Hydrocarbon pool based reactions donate olefins and methyl-benzenes as primary products in a continuous-flow MTH reaction; when the dwelling time of product extends intra-conversions $\left(\mathrm{H}_{2}\right.$ transfers) between products would further adjust the composition of MTH yield, in which case alkanes and aromatic products (cokes precursors) increase. In the case of intraconversions are ignored due to limited product dwelling time, thermodynamic calculation on Gibbs free energy
\end{abstract}

Electronic supplementary material The online version of this article (doi:10.1007/s13203-017-0178-1) contains supplementary material, which is available to authorized users.

Peter P. Edwards

peter.edwards@chem.ox.ac.uk

Tiancun Xiao

xiao.tiancun@chem.ox.ac.uk

1 State Key Laboratory of Heavy Oil Processing, China University of Petroleum (Beijing), 18 Fuxue Road, Beijing, China

2 Inorganic Chemistry Laboratory, Department of Chemistry, KACST-Oxford Petrochemical Research Centre (KOPRC), University of Oxford, Oxford, UK

3 Petrochemical Research Institute, King Abdulaziz City for Science and Technology, P. O. Box 6086, Riyadh 11442, Kingdom of Saudi Arabia change of selected sub reactions shows fairly close results to the real experimental data, which well supports the above explanations. This work highlights the importance of proper choosing target products and/or sub reactions for a rational thermodynamic prediction of MTH product distribution obtained in time-on-stream.

Keywords Methanol to hydrocarbon - Hydrocarbon pool mechanism · Thermodynamic · Intra-conversion · Dwelling time

\section{Introduction}

At present, the pathways of methanol to hydrocarbon reaction especially the formation of first $\mathrm{C}-\mathrm{C}$ bond are still in debate. The most acceptable hypothesis by far relies on the mechanism based on a 'hydrocarbon pool' [1]. In this theory, limited trace amount of hydrocarbons introduced as impurities in the methanol feedstock formed the initial aromatics (some benzene ring structures), which play a key role as the 'scaffold' in later process [2]. Methyl groups are added onto the hydrocarbon pool molecules in alkylation steps and light olefins are subsequently formed by the corresponding de-alkylation steps. The initial olefins can be converted into alkanes by occupying $\mathrm{H}_{2}$, whereas continuous loss of $\mathrm{H}_{2}$, followed by the cyclization steps forms more aromatics [3-5]. In a mature MTH system, series of the above reactions proceed in a parallel way and, therefore, bring in a complexity to the products and orders of their formation; however, thermodynamics always say coke (extremely dehydrogenated products, or solid carbons) is the dominating product in MTH and most other hydrocarbon transformations [6]. Before the reaction reaches a final format of solid carbons $\left[\mathrm{C}_{(\mathrm{s})}\right]$, 
dehydrogenation and polymerization are predominant in the system and extremely favoured by the thermodynamics [7-9]. The purpose of thermodynamic investigation is to predict a useful product distribution when the reactions reach to an equilibrium state, so researchers should make a choice on the reactions related in the system. In an attempt to take thermostable products, including cokes, $\mathrm{CO}$ and $\mathrm{CO}_{2}$, into the thermodynamic calculations, previous studies embodied extremely limited gas olefins and aromatics in product yields [9]. In a similar system of methane aromatization, it was also found benzene yield closing to real experimental results could only be calculated when solid carbons are not included [10]. Hence, one critical issue should be highlighted before the thermodynamic calculation is "how we could adjust the simulation/calculation to explain/predict our results".

The thermodynamic investigation in this study was originally designed for a rational understanding of results from our previous MTH lab experiments, including a 6 bar pressure, catalyst loading amplified $(20 \mathrm{~g})$ reaction, and two atmosphere reactions for nano H-ZSM-5 deactivation $\left(8 \mathrm{~h}^{-1}\right.$ Weight Hourly Space Velocity, WHSV) and industrial H-ZSM-5 performance tests, respectively. Like other researches, in our experiments methanol conversion mainly yield large portion of gas alkanes, gas olefins, as well as aromatics $[4,5,11]$. This is owing to the continuous flow of methanol feedstock and the non-stop transportation of previous formed products to the outside of the system (before the catalyst deactivates); in other words, the reaction happens in an opening system, which greatly reduces the chances of coke formation.

Strangely, even adjustments were made to selectively remove coke, $\mathrm{CO}$, and $\mathrm{CO}_{2}$ from the calculation, the predicted product distributions from thermodynamic calculation are still quite different from the practical experimental observations; gas olefins are still in very poor portions in strong comparison to the alkanes. The founded problems also occurred in previous studies $[9,10]$. Therefore, for a more accurate prediction on olefin formation, we have focused more on the simulations employing olefins $\left(\mathrm{C}_{2}-\right.$ $\left.\mathrm{C}_{4}\right)$ and/or aromatics $\left(\mathrm{C}_{6}-\mathrm{C}_{9}\right)$ as the target products.

According to the hydrocarbon pool theory, olefins are earlier formed in the system where aromatics (some of them are also formed in an early time as the hydrocarbon pools) and alkanes can be obtained in later $\mathrm{H}_{2}$ transfers (intra-conversion between products, via $\mathrm{H}_{2}$ loss/addition) [12]. It seems that the longer the olefins stay in the system, the more they are consumed. Hence, great interests and attentions should be made on the reaction dwelling time of products in a real non-stopping reaction system, which may play a key role in understanding the difference between ideal thermodynamic results and real MTH yields.
Initial work-thermodynamic calculations on selected sub reactions

Changes of reactions in Gibbs free energy $\left(\Delta_{r} G_{m}^{\theta}\right)$ and products equilibrium constants $\left(K^{\theta}\right)$ of selected $25 \mathrm{sub}$ reactions are calculated in the temperature range of 200-1000 ${ }^{\circ} \mathrm{C}$. Although the MTH mechanism is in a great complexity, thermodynamics are not affected by the reaction routes. The selected 25 reactions have covered all the directions from methanol to the major MTH products $\left(\mathrm{C}_{1}-\right.$ $\mathrm{C}_{9}$ ) with essential product intra-conversions, and are supposed to happen in a real MTH system proceeding in timeon-stream [11, 12]. Particularly, we have further separated the isomers of xylene and tri-methylbenzene, for a more comprehensive study than the previous works, and a consideration that para-xylene might be the most favourable product in the methanol to aromatics process via H-ZSM-5 zeolite [4, 8, 9]. The intra-conversions between different xylenes and the reactions of toluene to benzene and xylenes are specially considered, highlighting the importance of BTX products (benzene, toluene and xylenes) in the total aromatics. The selected 25 sub-reactions are listed in below:

- The Gibbs free energy changes $\left(\Delta_{r} G_{\mathrm{m}}^{\theta}\right)$ for each subreaction in the temperature range of $200-1000{ }^{\circ} \mathrm{C}$ were calculated as following (1)-(5):

$$
\begin{gathered}
\Delta_{r} H_{m}^{\theta}(298.15 \mathrm{~K})=\sum \Delta_{f} H_{m}^{\theta}(298.15 \mathrm{~K})_{P} \\
\quad-\sum \Delta_{f} H_{m}^{\theta}(298.15 \mathrm{~K})_{R} \\
\begin{aligned}
& \Delta_{r} H_{m}^{\theta}(T)= \Delta_{r} H_{m}^{\theta}(298.15 \mathrm{~K}) \\
&+ \int_{298.15}^{T}\left[\sum\left(C_{p, m}\right)_{P}-\sum\left(C_{p, m}\right)_{R}\right] \mathrm{d} T \\
& \Delta_{r} S_{m}^{\theta}(298.15 \mathrm{~K})=\sum S_{m}^{\theta}(298.15 \mathrm{~K})_{P}-\sum S_{m}^{\theta}(298.15 \mathrm{~K})_{R}
\end{aligned}
\end{gathered}
$$

$\Delta_{r} S_{m}^{\theta}(T)=\Delta_{r} S_{m}^{\theta}(298.15 \mathrm{~K})+\int_{298.15}^{T}\left(\frac{C_{p, m}}{T}\right) \mathrm{d} T$

$\Delta_{r} G_{m}^{\theta}(T)=\Delta_{r} H_{m}^{\theta}(T)-T \Delta_{r} S_{m}^{\theta}(T)$

- The standard equilibrium constant $\left(K^{\theta}\right)$ of each reaction at a particular temperature $(T)$ was calculated by Eq. (6):

$K^{\theta}(T)=\exp \left[-\Delta_{r} G_{m}^{\theta}(T) / R T\right]$

In the calculations above, $\Delta_{f} H_{m}^{\theta}$ represents the standard molar enthalpy of formation, $S_{m}^{\theta}$ stands for the standard molar entropy, while $C_{p, m}$ is the parameter of molar heat capacity at constant pressure. The input information for each chemical involved are listed in the following Table 1. $\Delta_{r} G_{m}^{\theta}$ of each reactions are calculated from $\Delta_{r} H_{m}^{\theta}$ and $\Delta_{r} S_{m}^{\theta}$ 
Table 1 Standard thermochemical properties of concerned substances, the relevant data are from classic physical chemistry hand books [14-16]

\begin{tabular}{|c|c|c|c|c|c|c|c|}
\hline \multirow[t]{2}{*}{ Substance } & \multirow{2}{*}{$\begin{array}{l}\Delta_{f} H_{\mathrm{m}}^{\theta}(298.15 \mathrm{~K}) \\
\mathrm{KJ} / \mathrm{mol}\end{array}$} & \multirow{2}{*}{$\begin{array}{l}S_{m}^{\theta}(298.15 \mathrm{~K}) \\
\mathrm{KJ} / \mathrm{mol}\end{array}$} & \multicolumn{5}{|c|}{$C_{\mathrm{m}, \mathrm{p}} / R=A+B T+C T^{2}+D T^{3}+E T^{4}$} \\
\hline & & & $A$ & $B \times 10^{3}$ & $C \times 10^{5}$ & $D \times 10^{8}$ & $E \times 10^{11}$ \\
\hline $\mathrm{CH}_{3} \mathrm{OH}$ & -200.10 & 126.8 & 4.714 & -6.986 & 4.211 & -4.443 & 1.535 \\
\hline $\mathrm{H}_{2}$ & 0 & 130.680 & 2.883 & 3.681 & -0.772 & 0.692 & -0.213 \\
\hline $\mathrm{CH}_{4}$ & -74.6 & 186.3 & 4.568 & -8.975 & 3.631 & -3.407 & 1.091 \\
\hline $\mathrm{C}_{2} \mathrm{H}_{4}$ & 52.5 & 219.3 & 4.221 & -8.782 & 5.795 & -6.729 & 2.511 \\
\hline $\mathrm{C}_{2} \mathrm{H}_{6}$ & -84.0 & 229.1 & 4.178 & -4.427 & 5.660 & -6.651 & 2.487 \\
\hline $\mathrm{C}_{3} \mathrm{H}_{6}$ & 20 & 266.6 & 3.834 & 3.893 & 4.688 & -6.013 & 2.283 \\
\hline $\mathrm{C}_{3} \mathrm{H}_{8}$ & -103.8 & 270.2 & 3.847 & 5.131 & 6.011 & -7.893 & 3.079 \\
\hline $1-\mathrm{C}_{4} \mathrm{H}_{8}$ & 0.1 & 305.6 & 4.389 & 7.984 & 6.143 & -8.197 & 3.165 \\
\hline $\mathrm{C}_{4} \mathrm{H}_{10}$ butane & -125.6 & 310.1 & 5.547 & 5.536 & 8.057 & -10.571 & 4.134 \\
\hline Benzene & 82.6 & 269.2 & 3.551 & -6.184 & 14.365 & -19.807 & 8.234 \\
\hline $\mathrm{C}_{7} \mathrm{H}_{8}$ & 50.4 & 320.7 & 3.866 & 3.558 & 13.356 & -18.659 & 7.690 \\
\hline PX & 18.00 & 352.4 & 4.113 & 14.909 & 11.810 & -16.724 & 6.736 \\
\hline MX & 17.3 & 357.7 & 4.002 & 17.537 & 10.590 & -15.037 & 6.008 \\
\hline $\mathrm{OX}$ & 19.1 & 352.8 & 3.289 & 34.144 & 4.989 & -8.335 & 3.338 \\
\hline Ethylbenzene & 29.90 & 360.5 & 4.544 & 10.578 & 13.644 & -19.276 & 7.885 \\
\hline $\mathrm{C}_{9}-123$ & -9.50 & 381.890 & 4.042 & 31.152 & 10.185 & -16.262 & 6.922 \\
\hline $\mathrm{C}_{9}-124$ & -13.81 & 390.158 & 5.319 & 20.074 & 12.034 & -16.873 & 10.465 \\
\hline $\mathrm{C}_{9}-135$ & -15.90 & 377.761 & 5.305 & 20.039 & 11.606 & -16.317 & 6.852 \\
\hline
\end{tabular}

All data refer to $298.15 \mathrm{~K}$ and 1 bar pressure. $R$ is ideal gas constant $[8.314472 \mathrm{~J} /(\mathrm{K} \mathrm{mol})]$

at the target temperature. Subscripts $(P$ and $R)$ are used for 'product' and 'reactant', respectively. The functions are based on previous studies in this area [7, 13]. and have been adjusted to the current study. The calculated $\Delta_{r} H_{m}^{\theta}, \Delta_{r} G_{m}^{\theta}$ and $K^{\theta}$ data are included in the supporting documents.

The calculations on the thermodynamics of individual sub reaction are included as the basis work of, and part of the essential studies referring to the later analysis. For such calculations, one disadvantage that may concern in the prediction of real experimental results is that assumptions have been made that each sub reaction proceeds without the influence of others, although they may be in a great certain to proceed in a parallel way in a real MTH system. At this point, previous studies recalled computer aided simulations which have integrated all the possible sub reactions and, therefore, might give a more comprehensive result $[8,9]$. In this work, we have achieved a more comprehensive computer-aided (CA) simulation from which the results have integrated all the possible influences between different sub reactions, and, therefore, might give a more indicative result for real industrial applications. Advantages of such a method base on the ability to solve chemical system (i.e. MTH system) proceeding in "blackbox" of uncertainty. Notably, in reality it is impossible to have the MTH reaction finish completely into the form of cokes; on the contrary, similar to the lab experiments, any
MTH reaction in an industry-scale reactor or pilot instrument would be a non-stopping, products-continuously being-removed process, and particularly when the product selectivity obtained by the employed porous zeolites (e.g. H-ZSM-5) works to affect the yields, the calculations on single sub reaction do denote important implications for the product compositions achieved in various conditions. ${ }^{1}$

\footnotetext{
1 We note other researchers may question on how the thermodynamic calculations on single sub reactions could be more illustrative to a real situation in a pilot plant or in an industry scale reactor where parallel reactions do happen and interactions between different reactions are unavoidable. Despite those interactions between sub reactions are neglected in such calculation on single sub reaction, the results, without the interference from others, do better illustrate the intrinsic chemistry of a sub reaction. The data may be obtained more theoretically; however, they are still very allusive for the real MTH applications in industry, where we will observe a non-stopping, hydrocarbons (i.e. gas olefins, and liquid aromatics) rich product yield rather than the only coke formation which is the final result of unadjusted computer-aided simulations (these simulations do have considered all the possible sub reactions, or, as they base on the Gibbs energy minimization the concerns on interactions between sub reactions are no longer a problem). Here we comment that all the thermodynamic methods are employed to reference to the real observations, and their utility should be based on the observations from real reactions, no matter in laboratory or industrial scale, there are non-stopping, coking avoiding processes, where the focus on single, undisturbed sub reaction, e.g. methanol $\rightarrow \mathrm{C}_{2}$, is very indicative.
} 


\section{Computer-aided simulations for three reactions of different conditions}

Equilibrium compositions of product mixture in the temperature range of $200-1000{ }^{\circ} \mathrm{C}$ are simulated for reactions under different reaction conditions for comparison with the lab test results. The simulations were employed by ASPEN Plus process simulation with the RGibbs model. The computer-aided simulation possesses many advantages when applied to a complex system in which multiple reactions processing in a parallel way, and the minimum reaction Gibbs free energy calculation has overcome the difficulty caused by the un-certained reaction routes and the interferences between different sub reactions $[9,10]$.

One unique important difference between the results of computer-aided (CA) simulation and the real lab-experiments is the extent of reaction process that might be taken into the calculation. Beyond all doubts, the CA simulation has been based on the assumption that the reaction has finally reached to the 'extreme' equilibrium; for instance, the methanol conversion happens in a close system for a termless period, thus, the layout of the results somehow reflect an 'ideal' product distribution which may never occur in reality. On the contrary, the lab tested results and even the real industrial plant outputs are obtained from a 'non-stoping', and continuos flow system. It is nearly impossible to have the whole system to reach a 'final' status (all cokes in this case), although some coking positions might have reached a close status. In our study, coke formation was not involved for results close to a 'processing' product output; however, it was found even $\mathrm{CO}$, $\mathrm{CO}_{2}$ were predominant in the simulated product composition, and this is similar to the case that coke is involved (Fig. S1). Obviously, the selectivity of our catalysts and the limited dwell time of primary products in the catalyst system gives a very small chance for $\mathrm{CO}$ and $\mathrm{CO}_{2}$ to occur in the final product yield. The process simulation results without $\mathrm{CO}$ and $\mathrm{CO}_{2}$ show closer to the real lab observations (Fig. S2), but the product distribution is limited to aromatics mainly. These problems in thermodynamic analysis, caused by extremely thermostable, but un-desirable products occurred in previous studies, and a rational solution normally prefer to ignore them in the calculations, for results better referenced to real lab observations $[9,10]$.

Our optimized simulation targets on the yield of major gas olefinic products (MTO) and aromatics (MTA) from MTH reactions in a ZSM-5 catalyst system. Former study obtained results closer to real experimental data when employed analogous methods [9]. However, our assumption is based on the 'hydrocarbon-pool' cycle, which has been considered as the origin of series of MTH reactions and gives $C_{2}-C_{4}$ olefins and methyl-aromatics as the primary products [4]. Further consideration is given to the fact that latter stage hydrogen transfer may convert these primary products into either saturated hydrocarbons (alkanes) or graphite species (deeply dehydrogenated cokes), and these intra-conversions indeed play an important role in deciding the following catalytic process, and the final product yields $[3,4,11,12]$. This simulation also takes the advantage that all of these 'hydrocarbon-pool' primary products $\left(\mathrm{C}_{2}-\mathrm{C}_{4}\right.$ olefins and $\mathrm{C}_{6}-\mathrm{C}_{9}$ aromatics) take a large portion in the product yield of short time (a few minutes to several hours) lab reactions and industrial applications $[4,5]$.

In the present research, we have simulated 3 individual MTH reactions of different conditions in a wide temperature range of $200-1000{ }^{\circ} \mathrm{C}$, and matched them with data from corresponding lab experiments (at single temperature points). Figure 1 shows the overall temperature dependent product distributions of a selected reaction ( 6 bar pressure, methanol/ $\mathrm{N}_{2}=1: 2$ in mole), and results of other two reactions are included in the supplementary (for the three reactions, simulations with gas alkanes, and $\mathrm{CO}$ as well as $\mathrm{CO}_{2}$ are also included, see Figs. S3-S8). ${ }^{2}$

The simulated product distributions of different reactions are quite similar, showing a general trend of increasing selectivity to aromatics as the reaction temperature goes up. The single benzene ring aromatics always take the largest portion in the product, and methyl-benzenes (Toluene, xylenes and tri-methyl benzenes) reached a maximum selectivity in the temperature section of $300-400{ }^{\circ} \mathrm{C}$, whereas benzene become predominant in the product distribution at temperatures of $400{ }^{\circ} \mathrm{C}$ and above.

The Fig. 2a-c show part of the products distributions without data of benzene and toluene, in the most widely applied methanol conversion temperatures $\left(200-550{ }^{\circ} \mathrm{C}\right)$. It was found methanol concentration in feedstock (reflected by the ratio to $\mathrm{N}_{2}$ ) only has limited impacts on the simulation data. The two reactions under atmosphere pressure exhibit quite close results with tiny difference (Fig. 2b, c). Notably, higher pressure caused observable shift of maximum product selectivity from the higher temperature zone to lower temperatures. An apparent evidence is the maximum M-xylene (MX) selectivity under 6 bar pressure, occurs at below $250{ }^{\circ} \mathrm{C}$ (Fig. 2a), whereas the corresponding maximum (as reflected by the peak centre in the figures) under atmosphere pressure occurs at about $275{ }^{\circ} \mathrm{C}$ (Fig. 2b, c). Our simulation well supports the real experimental observations that higher pressure and a lower

\footnotetext{
$\overline{2}^{2}$ Here the $\mathrm{N}_{2}$ in system do affect the calculations, but, with only the influence on the system pressures. For the reason to give a more real simulation to the lab/industrial reactions (the protective and inert gases are routinely used for pressure-supplier and flow carrier), we have employed the $\mathrm{N}_{2}$ as an inert content to adjust/balance the system pressures employed by our CA simulations, notably, $\mathrm{N}_{2}$ will not enter any chemistry in MTH reaction.
} 


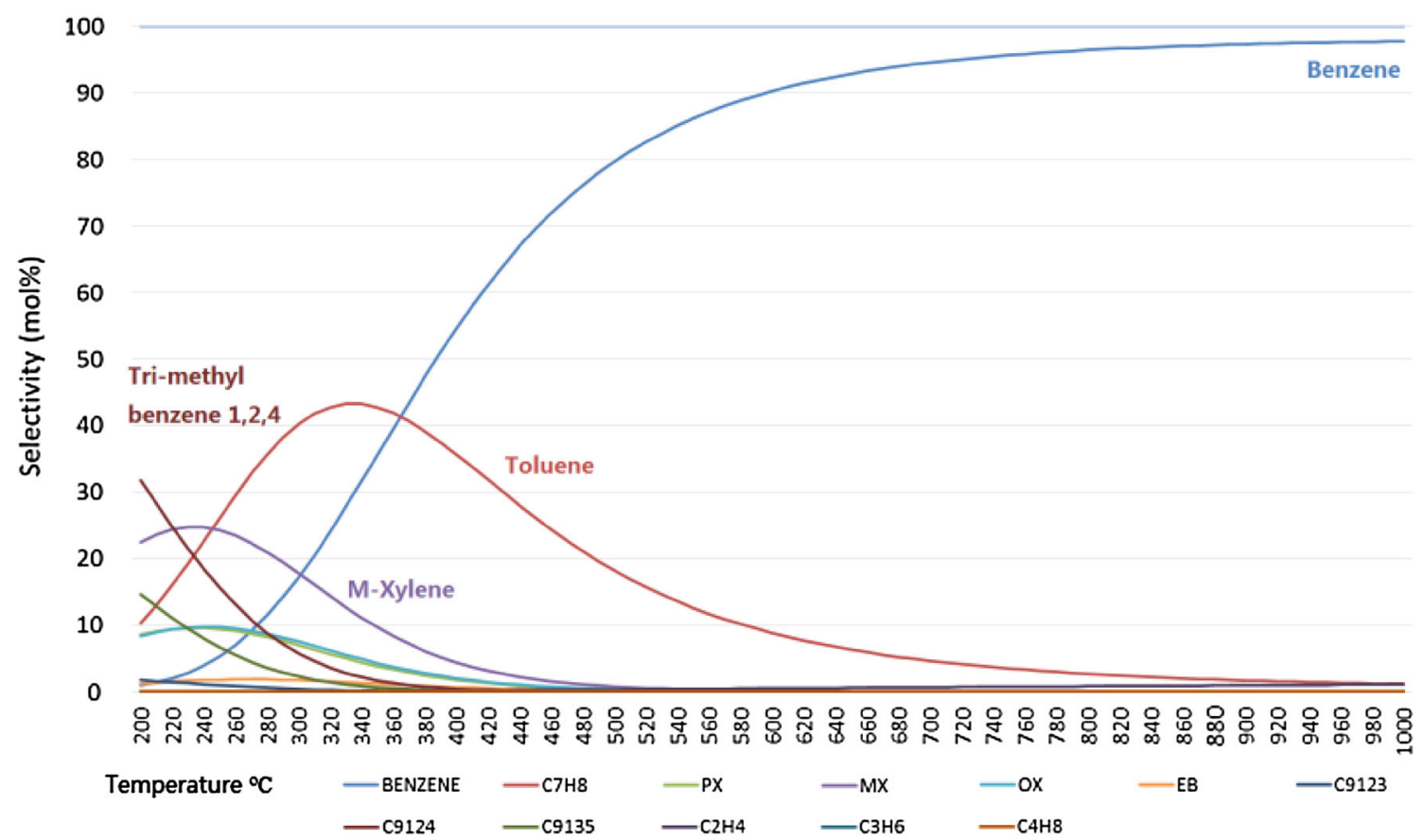

Fig. 1 Distribution of different products, only olefins are included as the $\mathrm{C}_{1}-\mathrm{C}_{4}$ product in the simulation $\left(200-1000{ }^{\circ} \mathrm{C}\right)$; 6 bar pressure, methanol $(\mathrm{mol}) / \mathrm{N}_{2}(\mathrm{~mol})=1: 2,1$-butene, and $n$-butane
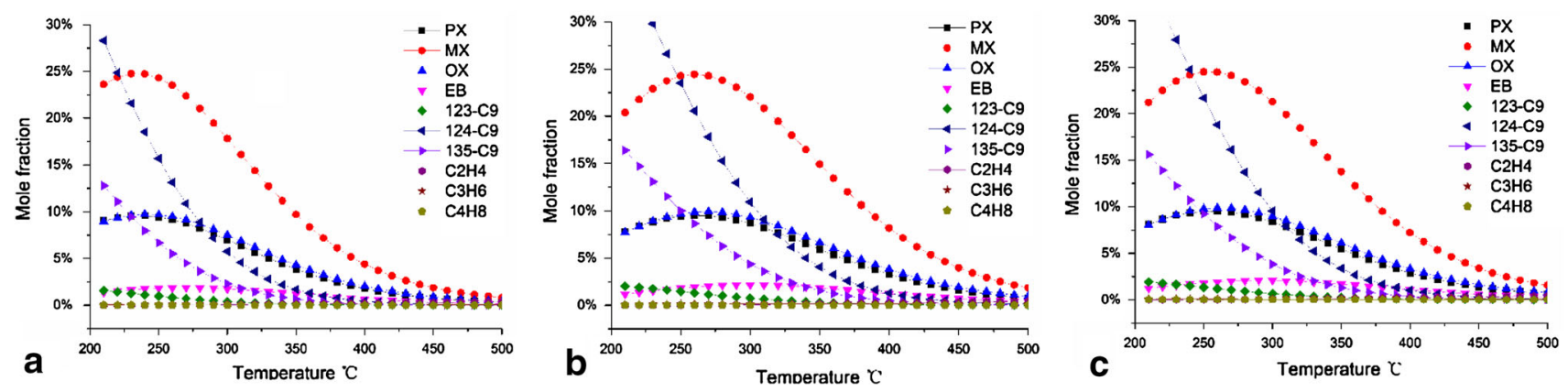

Fig. 2 Product distribution of different products, only olefins are included as the $\mathrm{C}_{1}-\mathrm{C}_{4}$ product in the simulation, benzene and toluene data $\left(200-500{ }^{\circ} \mathrm{C}\right)$ are not shown; reaction conditions: a $450{ }^{\circ} \mathrm{C}$, 6 bar pressure, methanol $(\mathrm{mol}) / \mathrm{N}_{2}(\mathrm{~mol})=1: 2$, 1-butene, and $n$ -

temperature may benefit the yield of aromatics [2, 11, 17, 18].

Inhibition of light olefin products has been reflected in the results (Fig. 3a-c) obtained in each reaction, showing formation of olefins is not thermodynamically favoured under the applied conditions. In the temperature range of $300-500{ }^{\circ} \mathrm{C}$, which was indicated to donate large portions of $\mathrm{C}_{2}-\mathrm{C}_{4}$ olefins in the previous researches, $[3,5,12,19]$, ethylene selectivity is higher than other two olefin types, and shows a gradually increasing trend. It seems $\mathrm{C}_{4} \mathrm{H}_{8}$ (1-butene) is greatly supressed in each case, as reflected by the observed data. Propylene selectivity experienced a peak at about $300{ }^{\circ} \mathrm{C}$, which is slightly higher under lower pressure conditions. Notably, all $\mathrm{C}_{2}-\mathrm{C}_{4}$ olefins are further suppressed by 6 bar pressure (Fig. 3 a). butane; b $450{ }^{\circ} \mathrm{C}$ atm pressure, methanol $(\mathrm{mol}) / \mathrm{N}_{2}(\mathrm{~mol})=50: 1$, 1-butene, and $n$-butane; c $400{ }^{\circ} \mathrm{C}$ atm pressure, methanol $(\mathrm{mol}) / \mathrm{N}_{2}$ $(\mathrm{mol})=3: 1,1$-butene, and $n$-butane

\section{Conflictions between the simulated data and real experimental results}

For rational explanations on results from some of our previous works, a group data showing the product distributions (selectivity) at selected single temperature points (e.g. $450{ }^{\circ} \mathrm{C}$ ) were extracted from the simulated results and listed in the Table 2. Correspondingly, in the Table 3, we have listed selected data (product yields) from experiments employing the same thermodynamic conditions as the simulation. Due to the limitation of equipment, it is hard to record the time on stream aromatics yield (full line heating between the reactor and GC helps in previous study, but has not been applied in this study) [12]; instead, $5 \mathrm{~h}$ total 

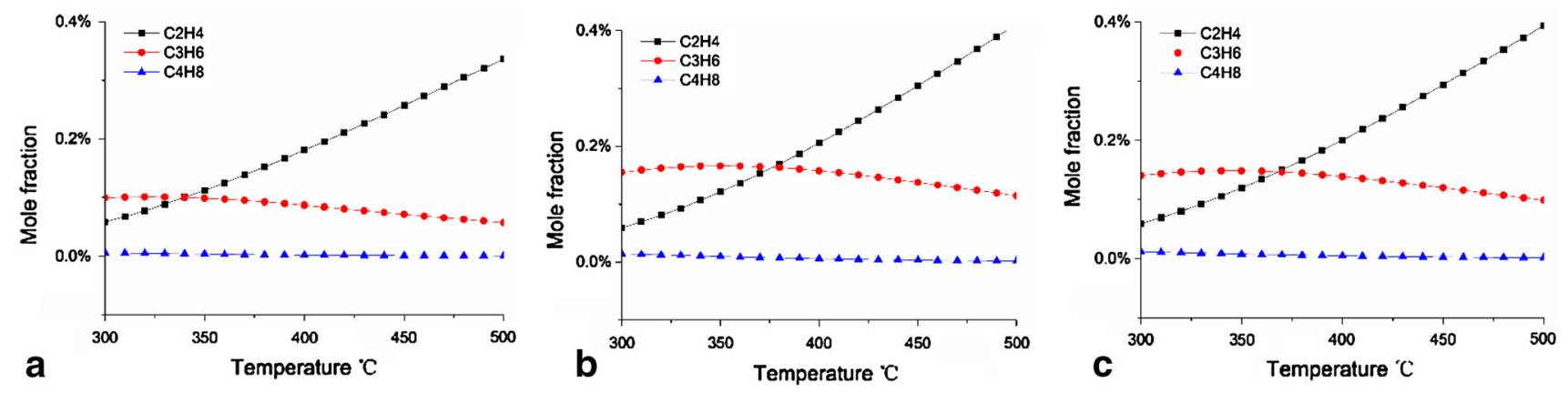

Fig. 3 Mole fractions of major olefin products, only olefins are included as the $\mathrm{C}_{1}-\mathrm{C}_{4}$ product in the simulation $\left(300-500{ }^{\circ} \mathrm{C}\right)$; reaction conditions: a $450{ }^{\circ} \mathrm{C}, 6$ bar pressure, methanol $(\mathrm{mol}) / \mathrm{N}_{2}$

aromatics yields were measured. The major gas product yields always change in time on stream, therefore, the data were chosen from the $5 \mathrm{~h}$ single time point. In most cases of our experiments, the amount of major gas products finally reached a stable and highest level by the end of the $5 \mathrm{~h}$ reaction time, thus reflect the best olefin and alkane yields (see Figs. S9-11).

Simulation in this study was originally designed for the prediction of experiments and later explanations. Interestingly, the CA simulated results are quite different from the real experimental data. In each case, aromatics are always dominant in the simulated product distributions, especially benzene, reaches up to $\sim 70 \mathrm{~mol} \%$ in the case of 6 bar pressure, and $450{ }^{\circ} \mathrm{C}$ reaction temperature with a methanol to $\mathrm{N}_{2}$ molar ratio of 1:2. Simulation shows higher pressure and smaller methanol to $\mathrm{N}_{2}$ ratio both contribute to higher benzene selectivity, and thus possess hindrance on other aromatic products and olefins. Toluene is also a favourable product type by the thermodynamic and takes a large portion in the simulated data. It seems that methyl groups on the aromatic ring structure have increased the reaction difficulty thermodynamically, as product selectivity decreases apparently from benzene to tri-methyl benzenes; this exists in the simulated data of all the three reactions.

Another important information from the above simulated data is the extremely poor olefin selectivity (less than $1 \mathrm{~mol} \%$ ) in strong comparison to the aromatics. However, for the selected three different MTH reactions, gas products always take a large portion in the real product distribution. In the reaction under 6 bar, and with a lower methanol $(\mathrm{mol})=1: 2$, 1-butene, and $n$-butane; $\mathbf{b} 450{ }^{\circ} \mathrm{C}$ atm pressure, methanol $(\mathrm{mol}) / \mathrm{N}_{2}(\mathrm{~mol})=50: 1,1$-butene, and $n$-butane; c $400{ }^{\circ} \mathrm{C}$ atm pressure, methanol $(\mathrm{mol}) / \mathrm{N}_{2}(\mathrm{~mol})=3: 1,1$-butene, and $n$-butane

conversion duty $\left(\right.$ WHSV $=1.5 \mathrm{~h}^{-1}$ ), aromatics yield has been promoted, but gas olefins and alkanes are still the major products. Observed yields of ethylene and propylene lie on a relatively low level, but still contribute to a total $3.77 \mathrm{~mol} \%$ in the product distribution. Reactions under atmosphere pressure donate much higher level of olefins, although other conditions are different in the selected two reactions. Notably, higher methanol to carrier gas $\left(\mathrm{N}_{2}\right)$ ratio may also contribute to the improved olefins yield, as shown in the simulated results of two atmosphere pressure reactions, with methanol to $\mathrm{N}_{2}$ ratio of $50: 1$ and $3: 1$, respectively. It is supposed that pressure is still the main reason for the totally different aromatic and olefin product distributions in each case, which is also supported by series of previous studies [1, 3-5, 19].

\section{Simulations and calculations vs. limited dwelling time}

Questions come from the huge difference in selectivity to gas olefins and aromatics between the simulated data and results from real MTH experiments. Obviously, the thermodynamic data are based on a perfect equilibrium status which may require an extremely long term reaction. Nevertheless, such a termless reaction, processing automatically, never occurs in both lab experiments and industrial applications, and it is nearly impossible to let MTH reaction be completely finished in a perfect status. The real reaction normally employs catalysts to promote certain steps, or some sub-directions of the whole reaction. Despite that the

Table 2 Major products yield (mol\%) of various conditions, only aromatics and gas olefins are considered in the products

\begin{tabular}{lllllllllllll}
\hline Conditions & Benzene & $\mathrm{C}_{7} \mathrm{H}_{8}$ & $\mathrm{PX}$ & $\mathrm{MX}$ & $\mathrm{OX}$ & $\mathrm{EB}$ & $\mathrm{C}_{9} 123$ & $\mathrm{C}_{9} 124$ & $\mathrm{C}_{9} 135$ & $\mathrm{C}_{2} \mathrm{H}_{4}$ & $\mathrm{C}_{3} \mathrm{H}_{6}$ & $\mathrm{C}_{4} \mathrm{H}_{8}$ \\
\hline 6 bar, $450{ }^{\circ} \mathrm{C}, 1: 2$ & 69.51 & 26.17 & 0.75 & 1.86 & 0.90 & 0.33 & 0.01 & 0.11 & 0.04 & 0.26 & 0.07 & 0.001 \\
Atm, $450{ }^{\circ} \mathrm{C}, 50: 1$ & 53.33 & 36.10 & 1.86 & 4.60 & 2.20 & 0.78 & 0.04 & 0.48 & 0.17 & 0.28 & 0.14 & 0.004 \\
Atm, $400{ }^{\circ} \mathrm{C}, 3: 1$ & 43.09 & 40.60 & 2.89 & 7.20 & 3.34 & 1.07 & 0.08 & 1.02 & 0.36 & 0.20 & 0.14 & 0.005 \\
\hline
\end{tabular}


Table 3 Major product yields (mol \%) from selected MTH experiments, aromatics were collected after $5 \mathrm{~h}$ reaction showing the total yield of the reaction period, gas product yields were measured at the $5 \mathrm{~h}$ time point on stream, conditions of each reaction were listed in the table

\begin{tabular}{|c|c|c|c|c|c|c|c|c|c|c|}
\hline Reactions and conditions & Benzene & $\mathrm{C}_{7} \mathrm{H}_{8}$ & $\begin{array}{l}\mathrm{PX} \text { and } \\
\mathrm{MX}\end{array}$ & $\mathrm{OX}$ & EB & $\mathrm{C}_{9}$ & $\mathrm{C}_{2} \mathrm{H}_{4}$ & $\mathrm{C}_{2} \mathrm{H}_{6}$ & $\mathrm{C}_{3} \mathrm{H}_{6}$ & $\mathrm{C}_{3} \mathrm{H}_{8}$ \\
\hline $\begin{array}{l}6 \text { bar, } 450{ }^{\circ} \mathrm{C}, 1: 2 \text {, nano H-ZSM-5 }(\mathrm{Si} / \mathrm{Al}=60) \text {, } \\
\quad \text { WHSV }=1.5 \mathrm{~h}^{-1}\end{array}$ & 3.36 & 14.42 & 16.16 & 4.40 & 2.35 & 7.13 & 1.28 & 2.82 & 2.49 & 17.50 \\
\hline $\begin{array}{l}\text { Atm, } 450{ }^{\circ} \mathrm{C}, 50: 1 \text {, nano H-ZSM-5, }(\mathrm{Si} / \mathrm{Al}=60) \text {, } \\
\quad \text { WHSV }=8 \mathrm{~h}^{-1}\end{array}$ & 1.39 & 9.54 & 13.57 & 4.00 & 0.82 & 2.73 & 29.81 & 2.21 & 16.54 & 44.62 \\
\hline $\begin{array}{l}\text { Atm, } 400{ }^{\circ} \mathrm{C}, 3: 1 \text {, industrial H-ZSM-5, }(\mathrm{Si} / \mathrm{Al}=25) \text {, } \\
\text { WHSV }=2 \mathrm{~h}^{-1}\end{array}$ & 1.50 & 4.24 & 6.26 & 1.86 & 1.067 & 3.25 & 9.78 & 6.94 & 15.71 & 7.81 \\
\hline
\end{tabular}

final equilibrium will never be disrupted by the catalyst, the reaction routes can be changed, and the product distribution in output are, therefore, totally different from the thermodynamic favoured answer, especially when the reaction time is limited. Here the limited reaction time means a short dwelling time of the processing products in the system, which cannot be converted to the final form before being transported to the outside environment. This is the reason why benzene is not allowed to be dominant in the real reaction products, although it is greatly thermodynamically favoured by the equilibrium. It also helps in understanding of the much higher olefin yields, which may not be chosen by the thermodynamic conditions, but play an important role as intermediate products. Conflictions lying between the simulation data and experimental records, therefore, have highlighted the importance of reaction routes which decide the product yield from the system in a parallel way with the thermodynamics in the case that the reaction cannot be 'completely finished' thermodynamically, and actually, they indeed have some more influences on product selectivity when the reaction time is limited. ${ }^{3}$

\footnotetext{
${ }^{3}$ Here the reaction time, in terms of product dwelling time in the system is highlighted. Questions may come from that the changes of reaction flowrate or product shape selectivity (this affect the masstransfer in reaction therefore will change the efficiency of transportation for different products) could affect the product yields, thus, how the thermodynamic simulations be more indicative in such cases. Our comments are based on series of observed MTH reaction results obtained over different zeoltypes. The flowrate does affect the reaction time, and an over-accelerated methanol injection rate will definitely lead to a rapid coking of the catalyst, where the ideal thermodynamics could be achieved when all the chemicals in the MTH system (catalysts are not included) are converted into the cokes. In our simulation we have considered the domination of coking, and have selectively neglected this pathway for a better, closer results to real non-stopping reactions. One limitation would be lacking of the difference between different flowrates applied to a MTH system; in this case, as the product types are confirmed, the flowrate will no longer work on the product yields (the dwelling time will only decide the potential product types, e.g. the endless reaction will result in cokes only), as the thermodynamics are not affected.

As the MTH proceeds over zeolites of selective porous properties, the variation in zeotypes do affect the real product yields by influences on product/intermediate mass transfers. A good example is
}

In the hydrocarbon pool mechanism, if alkylation steps on benzene ring are considered as the 'starting point' of series reactions, the following steps would be the corresponding 'de-alkylation' during which the alkyl groups on the benzene ring structure are eliminated, released to the reaction system in terms of the primary light olefins [12]. These light olefins may be converted into alkanes, or form more aromatics via the aromatization steps in the later stages. It is supposed that in practical laboratory tests and industrial manufactures, olefin products are transported quickly to the outside environment, and present in the yields, thus have limited chance to be converted into aromatics. On the other hand, some portions of the primary olefins are converted into aromatics, with higher pressure putting a positive effect on this process. The thermodynamic simulation is closer to the case that the system is isolated with endless reaction time towards a perfect equilibrium. In the case that coke formation is selectively ignored (the formed aromatics are not further converted into the graphitic cokes), the alkylation step is first forced to be interrupted, as no methyl group from methanol is supplied. However, de-alkylation may not stop immediately, and more light olefins are released from the alkyl benzenes, then, converted into more aromatics in the later stage. As no methyl group is supplied from outside of the system, the aromatization of light hydrocarbons would stop at the benzene ring structure. As a result, benzene finally becomes predominant in the system and methyl aromatics have less methyl groups have more chances to exist in the final product. When the hydrocarbon pool mechanism is introduced for explanations on reaction route, the thermodynamic simulation data and real experimental results could be better matched.

\section{Footnote 3 continued}

routinely product with larger than zeolite pore sizes are impossible to be formed. However, such influence will not affect the results in thermodynamic simulations of selected products.

In fact, ahead of deciding the target products for simulations, the flowrate and shape selectivity issues, which affect the selection of products for research, have been considered already. 
On the other hand, the limited dwelling time further reduces the chance of the intra-conversions $\left(\mathrm{H}_{2}\right.$ transfers $)$ between the primary products which have been considered to possess unique impacts on the final product distributions $[3,4]$. Accordingly, the selectivity to a single product may more depend on a 'straight reaction route'. Our initial calculations on Gibbs free energy change indicate the thermodynamic barrier for different individual product formations directly from methanol (Fig. 4). These calculations have simplified the reaction by supposing only one target product is formed with only methanol and ignored product interactions. All the $\Delta_{r} G_{m}^{\theta}$ of different reactions are less than 0 in the temperature range from 200 to $600{ }^{\circ} \mathrm{C}$, which indicate that all the reactions are spontaneously in these temperature. The process simulation has considered all the reaction types including the interactions between different products (e.g. the transformation between different aromatics in Fig. 5).

The shape selectivity of different porous catalysts should also be considered. In a real MTH reaction over zeolite catalyst, e.g. H-ZSM-5, the product yield possesses large portion of gas olefins and alkanes, although they are greatly suppressed in the thermodynamic simulations. The channel diameter of ZSM-5 zeolite is close to the molecule size of single benzene ring aromatics, [4], thus limits the formation of larger aromatics. This also gives more opportunities for light molecules such as $\mathrm{C}_{2}-\mathrm{C}_{4}$ olefins to escape from the system in priority, and reduces the chance to be converted into aromatics. Gibbs free energy calculations on individual sub reactions show that methanol to olefins is thermodynamically favoured when each of the 25 sub reactions is isolated, in which case propylene and butane are easier to be formed than ethylene. When each sub reaction is isolated, the transformation of olefins to corresponding alkanes is also thermodynamically promoted, but gradually becomes inhibited at higher temperatures. Assumptions are made that the shape selectivity of zeolite allows selected reactions (e.g. methanol to olefins) to be more isolated. The related results are shown in the Fig. 6.

\section{Reaction pressure vs. product selectivity}

In the above discussions, all reactions employed a fixed pressure. By comparing simulations under 6 bar and atmosphere pressure (Figs. 2, 3) we noted higher pressure may benefit to the formation of aromatics while put suppressions on the olefins generation. When the reaction temperature is fixed, the influence of reaction pressure becomes more apparent, in both simulation data (Table 2) and experimental results (Table 3). Therefore, we have simulated the MTH reaction equilibrium selectivities of important olefins (ethylene, propylene and butylene) and aromatics (PX, MX, and OX; 123-trimethyl-benzene, 124-trimethyl-benzene and 135-trimethyl-benzene:

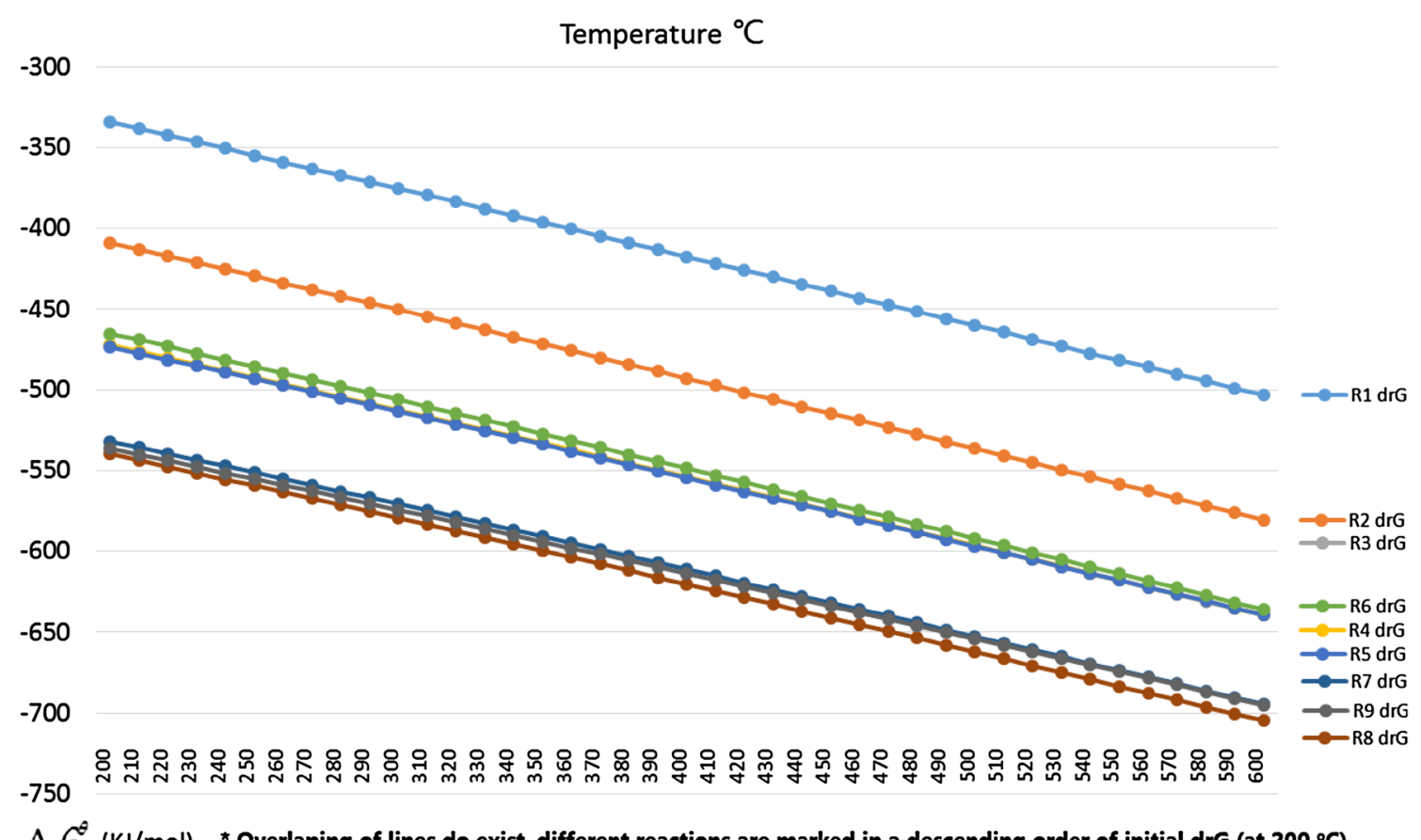

Fig. $4 \Delta_{r} G_{m}^{\theta}$ of methanol to benzene, toluene, ethyl-benzene, different xylenes and tri-methylbenzenes at $200-600{ }^{\circ} \mathrm{C}$ 
23

\section{Temperature ${ }^{\circ} \mathrm{C}$}

18

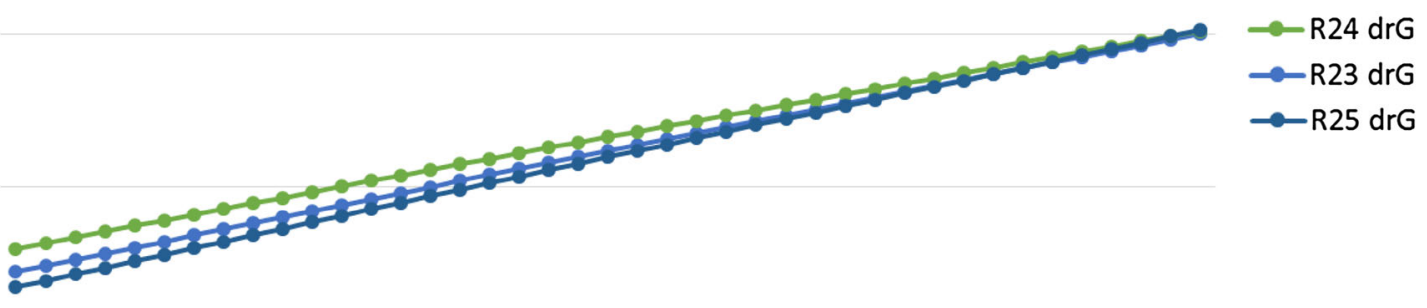

8

3 $-2$

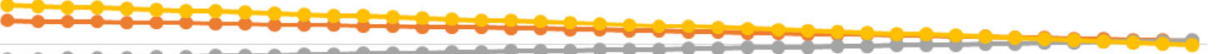

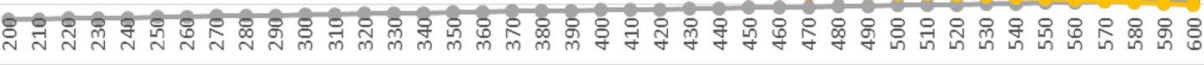
$-\mathrm{R} 22 \mathrm{drG}$
- R20 drG

$\Delta_{y} G_{z}(\mathrm{KJ} / \mathrm{mol})$ * Overlaping of lines do exist, different reactions are marked in a descending order of initial drG (at $\left.200{ }^{\circ} \mathrm{C}\right)$.

Fig. $5 \Delta_{r} G_{m}^{\theta}$ of the intra-transformations between benzene, toluene, and different xylenes (BTX) at $200-600{ }^{\circ} \mathrm{C}$

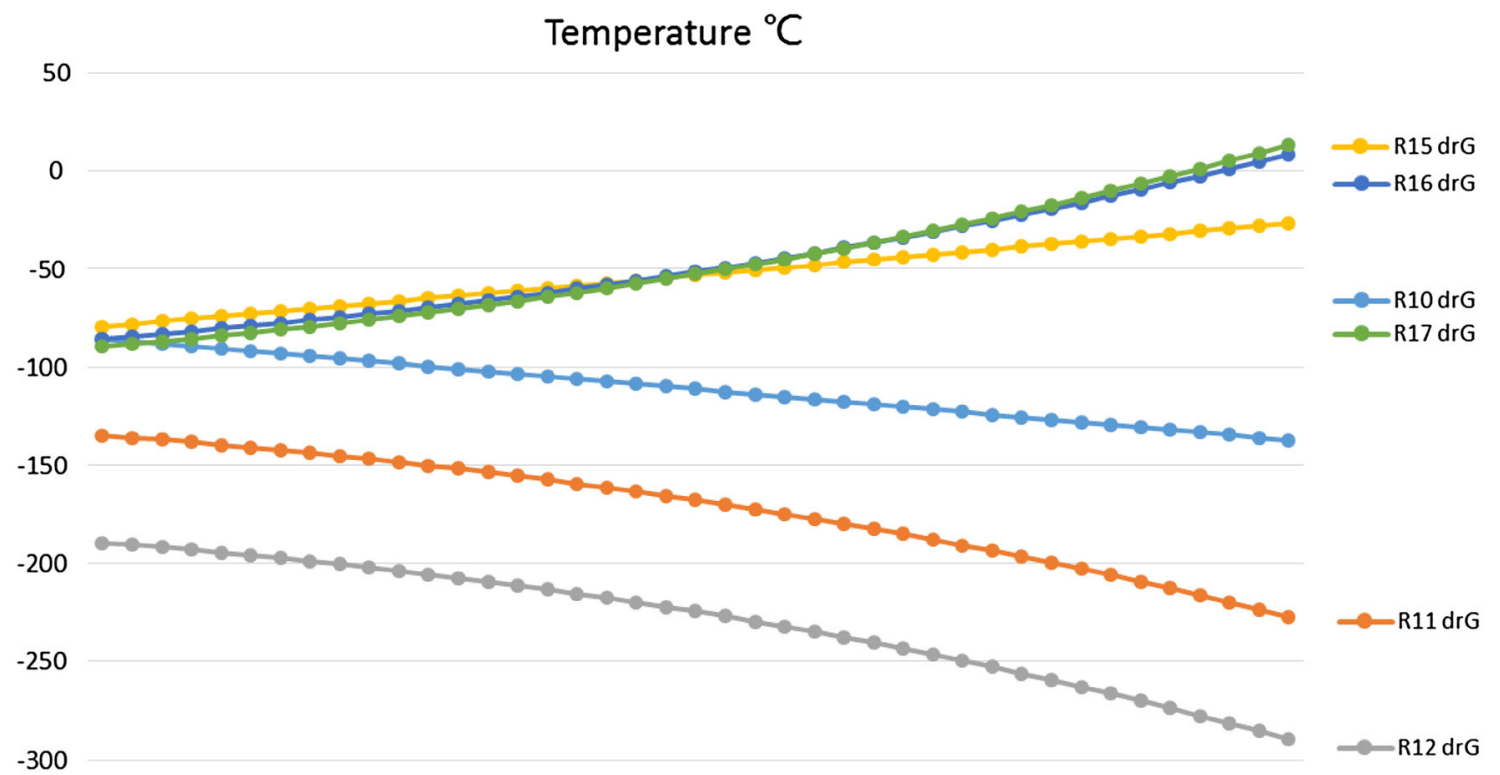

\section{$-350$}

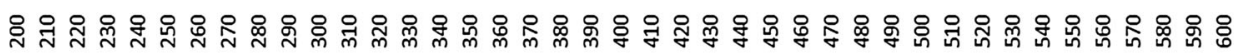

$\Delta_{z} G_{z}^{0}(\mathrm{KJ} / \mathrm{mol})$ * Overlaping of lines do exist, different reactions are marked in a descending order of initial drG (at $\left.200^{\circ} \mathrm{C}\right)$.

Fig. $6 \Delta_{r} G_{m}^{\theta}$ of methanol to olefins and gas olefins to alkanes at $200-600{ }^{\circ} \mathrm{C}$

benzene and toluene) products under the pressures of 0-10 bar, taking 2 bar as the gap between each simulation (Figs. 7, 8, 9, 10). Methanol is the only reactant and assumptions are made that the selected olefins and aromatics are the only products of system. In each figure, the curves show the selectivity change of a particular product as the temperature changes in $200-1000{ }^{\circ} \mathrm{C}$ under different pressures.

The results indicate higher pressure increases selectivity to the $\mathrm{C}_{2}-\mathrm{C}_{4}$ olefins, but the values are still quite small. 

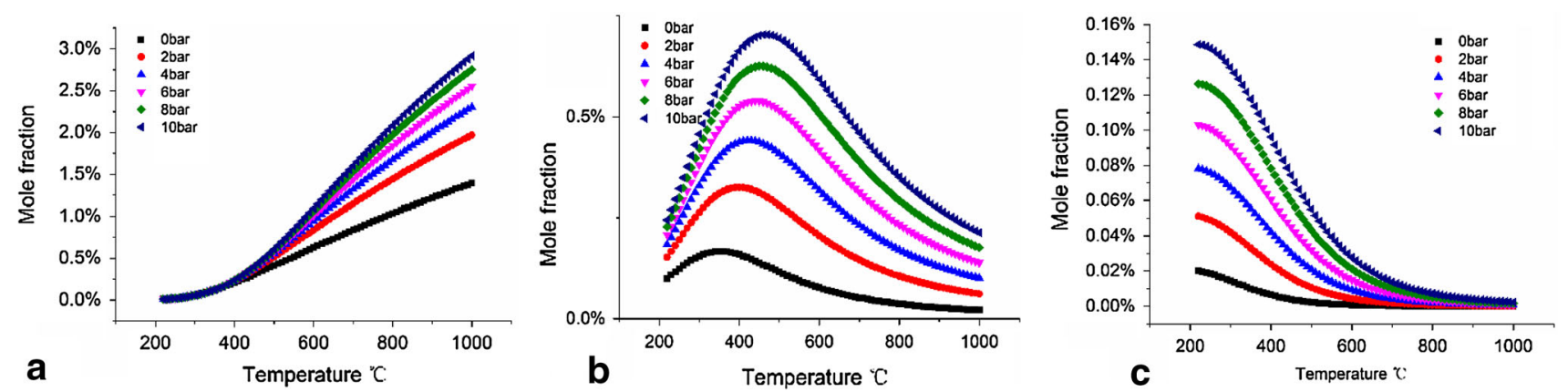

Fig. 7 Simulated equilibrium selectivity (mole fractions) of ethylene (a), propylene (b) and butylene (c) at varies pressures $\left(200-1000{ }^{\circ} \mathrm{C}\right)$, in the case that only olefins are included in major gas hydrocarbons, only methanol is injected into the system, without $\mathrm{N}_{2}$
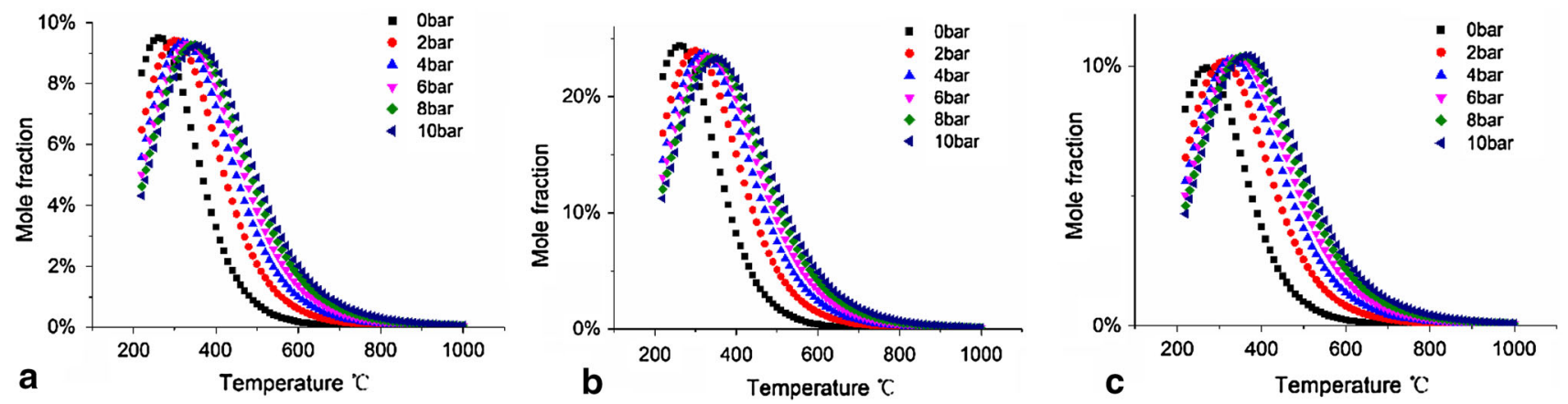

Fig. 8 Simulated equilibrium selectivity (mole fractions) of P-xylene (a), M-xylene (b) and O xylene (c) at varies pressures $\left(200-1000{ }^{\circ} \mathrm{C}\right)$, in the case that only olefins are included in major gas hydrocarbons, only methanol is injected into the system, without $\mathrm{N}_{2}$
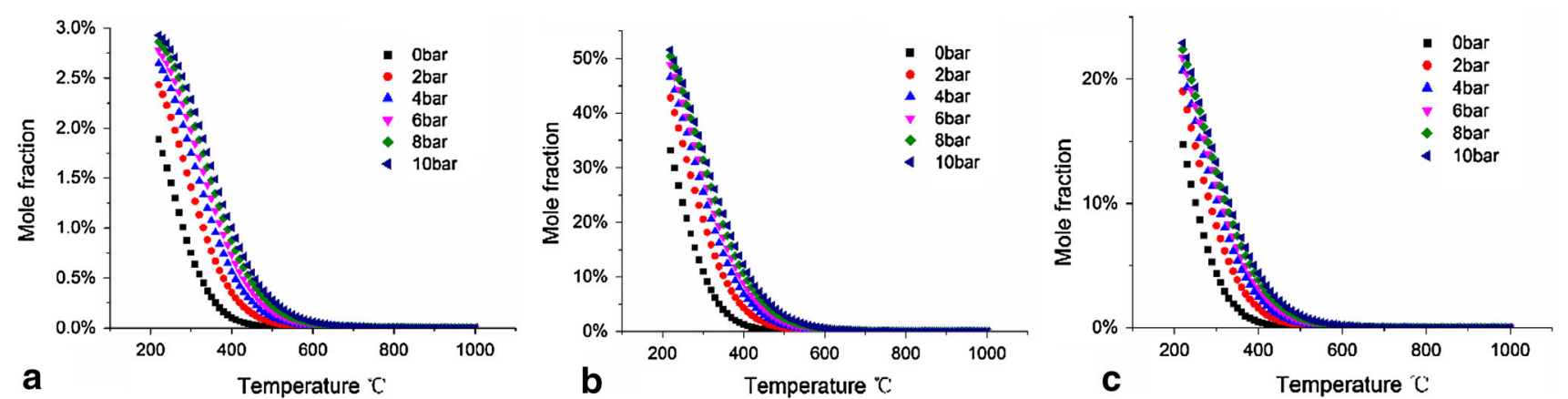

Fig. 9 Simulated equilibrium selectivity (mole fractions) of 1,2,3trimethyl-benzene (a), 124-trimethyl-benzene (b) and 135-trimethylbenzene (c) at varies pressures $\left(200-1000{ }^{\circ} \mathrm{C}\right)$, in the case that only

olefins are included in major gas hydrocarbons, only methanol is injected into the system, without $\mathrm{N}_{2}$

Fig. 10 Simulated equilibrium selectivity (mole fractions) of benzene (a) and toluene (b) at varies pressures $\left(200-1000{ }^{\circ} \mathrm{C}\right)$, in the case that only olefins are included in major gas hydrocarbons, only methanol is injected into the system, without $\mathrm{N}_{2}$
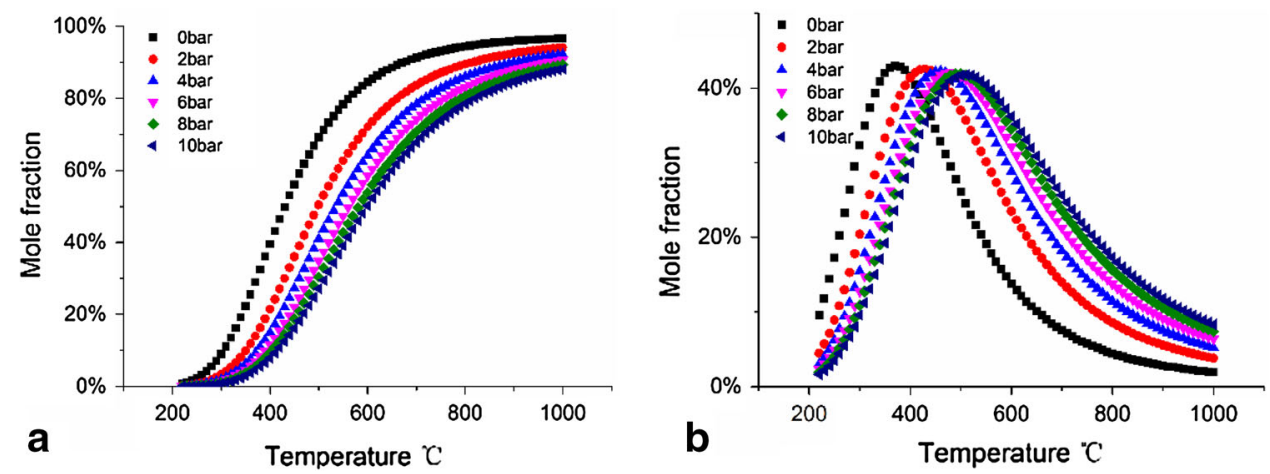
Under each pressure, ethylene selectivity goes up with the temperature while butylene drops in a dramatic trend and nearly disappears at temperatures of $600{ }^{\circ} \mathrm{C}$ and higher. On the other hand, propylene selectivity experienced a maximum at $300-500{ }^{\circ} \mathrm{C}$, and higher pressure obviously shifts this maximum from lower temperatures to higher. For xylenes, their selectivity also experienced a maximum as shown by the peak in the temperature range of $200-450{ }^{\circ} \mathrm{C}$. Interestingly, higher pressure does not promote higher selectivity to them, but just shift the maximum selectivity to higher temperatures. This is also the case for toluene. For tri-methyl benzenes, they do have higher selectivity when pressure goes up, but the general trend is, the selectivity drops rapidly as the temperature increases under a particular pressure. Similar to the early simulations, benzene always takes the largest portion in the product, its selectivity increases dramatically with the temperature, higher pressure just makes the maximum present earlier.

The above simulation results are closer to the real MTH reactions proceeding in time-on-stream, although the olefin selectivity is still tiny. Simulations considered alkanes, as well as $\mathrm{CO}$ and $\mathrm{CO}_{2}$ are also included in the supplementary data. Again, the results show either only aromatics or $\mathrm{CO}$ and $\mathrm{CO}_{2}$ are predominant in the products.

\section{Conclusions}

In this work, we started with the discussions on MTH mechanism. Then, 25 sub reactions were selected to represent the complex reaction system, and employed in the calculation of $\Delta_{r} H_{m}^{\theta}, \Delta_{r} G_{m}^{\theta}$ and $K^{\theta}$, taking the assumptions that each sub reaction proceeds individually. Considering that in real experiments all sub reactions (including the un-predicted pathways) are in a great certain to proceed in a parallel way where the interactions between different products cannot be ignored, process simulations with Aspen Plus were applied. To make a comparison, 3 real experiments were employed. The confliction between thermodynamic simulations and real experiment results are ascribed to the limited dwelling time of products in the MTH system, which is the truth in laboratory experiments and industrial applications. The thermodynamically favoured, more stable products, e.g. cokes, require termless reaction time, which is not achievable in time-on-stream. It has been noted that when cokes, $\mathrm{CO}, \mathrm{CO}_{2}$ and gas alkanes are ignored, the simulated results are closer to what have been observed in a real time-on-stream MTH reaction. In the selected three examples, it was found pressure possess important influences on the selectivity to major MTH products. Later simulations have examined the MTH product equilibrium selectivity at different temperatures (200-1000 $\left.{ }^{\circ} \mathrm{C}\right)$ under a variety of pressures (0-10 bar, with 2 bar as gap). Again, when selected olefins and aromatics are employed as the only MTH products, the simulations could be better referenced to the real experimental observations, with higher pressures were found to promote the aromatic formation. Interestingly, we note thermodynamic calculations (calculated $\Delta_{r} G_{m}^{\theta}$ ) on single sub reactions also help on the understanding of MTH product selectivity, particularly when the zeolite shape selectivity works in the reactions.

MTH process lies on a complexity of multiple (more than 20) sub reactions, yet the mechanism has not been completely confirmed. In this work, selective simplifying reaction product by focusing on olefins and aromatics was noted to better help on the prediction of real time-onstream observations. This is an optimized solution when considering the limited product dwelling time. Both thermodynamic calculations on single sub reactions and integrated simulations, when compared with real experimental data, have supported our suggestions.

Our discussions have focused on the major olefin and aromatic products in MTH reaction as part of the onerous simulations.

\section{Experimental}

Zeolite catalysts are imported from Lianxin Chemical Co. Ltd $(\mathrm{CN})$, the nano H-ZSM-5 zeolites are in rod shape, with diameters of $100-300 \mathrm{~nm}$. The industrial ZSM-5 sample is in micro size, and of $1-2.5 \mu \mathrm{m}$ in particle size. The conditions of each experiment are listed in the Table 2. In reaction $1,20 \mathrm{~g}$ of catalysts were loaded for an amplified lab experiment. The reactions 2 and 3 employed $1 \mathrm{~g}$ catalyst each time. The catalyst tests employed a fixed bed reactor system, connected with gas chromatography system (online GC, off line GC/MS). Catalyst sample powders were loaded in the middle of the tubular reactor, supported by silica sand (Fisher, 24 grit). Methanol (Sigma, reagent standard) was injected by a HPLC pump, and preheated in the preheater at $150{ }^{\circ} \mathrm{C}$ to fully vaporize into gas phase. $\mathrm{N}_{2}$ was used as carrier gas to bring the vaporized methanol into reactor. The gas and liquid products were well separated at the end of the system (cool water condenser used). Gas products were analysed with Shimadzu GC-2010SE GC system (RESTEK MXT-1HT column). The data were obtained from thermal conductivity detector (TCD) for non-hydrocarbons and flame ionized detector (FID) for hydrocarbons every $30 \mathrm{~min}$ after the methanol injection started. Liquid products were collected after the reaction and separated into water and oil phases. Each phase was analysed with Shimadzu GCMS-QP2010 Ultra High-end GC-MS system (SHIM-5MS column, Flame Ionized 
Detector).The catalyst testing system, and the tubular design are shown in the Fig. S12. The methanol conversion was determined by the amount of methanol remaining in the liquid product (both oil and water phases). Upon the current instrumental efficiency, and a requirement on continuous analysis of gas output every $30 \mathrm{~min}$, our research focuses on the TOS yield of major gas products including methane, ethane, ethylene, propane, propylene and a total $\mathrm{C}_{4}$. The value (mol\%) was calculated by comparing the instantaneous gas production with methanol injection rate. The corresponding yield to major liquid aromatics obtained after $5 \mathrm{~h}$ reaction, including benzene, toluene, and xylenes (BTX) as well as tri-methyl benzene was calculated from methanol consumption of selected products and total methanol injected. The definitions below are based on previous researches and modified to this research $[19,20]$.

Acknowledgements The authors would like to sincerely thank to other members of the PPE group at Oxford, and our colleagues of KACST at Saudi. For the excellent scalling-up design, we would like to give our applause to the Lianxin Chemistry Co. Ltd, and their consultancy in industrial implementations.

Open Access This article is distributed under the terms of the Creative Commons Attribution 4.0 International License (http:// creativecommons.org/licenses/by/4.0/), which permits unrestricted use, distribution, and reproduction in any medium, provided you give appropriate credit to the original author(s) and the source, provide a link to the Creative Commons license, and indicate if changes were made.

\section{References}

1. Dahl IM, Kolboe S (1994) On the reaction-mechanism for hydrocarbon formation from methanol over sapo-34.1. Isotopic labeling studies of the co-reaction of ethene and methanol. J Catal 149(2):458-464

2. Arstad B, Nicholas JB, Haw JF (2004) Theoretical study of the methylbenzene side-chain hydrocarbon pool mechanism in methanol to olefin catalysis. J Am Chem Soc 126(9):2991-3001

3. Ilias S, Bhan A (2013) Mechanism of the catalytic conversion of methanol to hydrocarbons. ACS Catalysis 3(1):18-31
4. Olsbye U et al (2012) Conversion of methanol to hydrocarbons: how zeolite cavity and pore size controls product selectivity. Angew Chem Int Ed. 51(Copyright (C) 2013 American Chemical Society (ACS). All Rights Reserved), pp 5810-5831

5. Stocker M (1999) Methanol-to-hydrocarbons: catalytic materials and their behavior. Microporous Mesoporous Mater 29(1-2):3-48

6. Guisnet M, Ribeiro RF (2011) Deactivation and regeneration of zeolite catalysts. Catalytic Science Series, ed. H.G. J., vol 9. Imperial College Press, London, p 340

7. Zhang $\mathrm{G}$ et al (2013) Aromatization of methanol I. Reaction thermodynamics. Shiyou Huagong 42(2):141-145

8. Zhang B-Z et al (2012) Thermodynamic study on methanol conversion to hydrocarbons (MTH). Fenzi Cuihua 26(6):546-553

9. Gunawardena DA, Fernando SD (2012) Thermodynamic equilibrium analysis of methanol conversion to hydrocarbons using Cantera methodology. J Thermodyn 125460:7

10. Spivey JJ, Hutchings G (2014) Catalytic aromatization of methane. Chem Soc Rev 43(3):792-803

11. Haw JF et al (2003) The mechanism of methanol to hydrocarbon catalysis. Acc Chem Res 36(5):317-326

12. Bjorgen $\mathrm{M}$ et al (2007) Conversion of methanol to hydrocarbons over zeolite H-ZSM-5: on the origin of the olefinic species. J Catal 249(2):195-207

13. Du X et al (2015) FDCDU15-catalytic dehydrogenation of propane by carbon dioxide : a medium-temperature thermochemical process for carbon dioxide utilisation. Faraday Discussions

14. Bruce E, Poling, JM (2000) The properties of gases and liquids. 5th edn. McGraw Hill, New York

15. Michael Frenkel GJK, Marsh KN, Roganov GN, Wilhoit RC (1994) Thermodynamics of organic compounds in the gas state, vol I. Thermodynamics Research Center (TRC), Texas USA

16. Speight JG (2005) Lange's handbook of chemistry. 70th Anniversary Edition ed. Mc-Graw Hill, New York, p 4192

17. Nováková J et al (1984) Catalytic activity of dealuminated Y and HZSM-5 zeolites measured by the temperature-programmed desorption of small amounts of preadsorbed methanol and by the low-pressure flow reaction of methanol. J Chem Soc Faraday Trans 1 Phys Chem Condens Phases 80(6):1457-1465

18. Chang C, Lang W, Smith R (1979) The conversion of methanol and other O-compounds to hydrocarbons over zeolite catalysts: II. Pressure effects. J Catal 56(2):169-173

19. Hereijgers BPC et al (2009) Product shape selectivity dominates the Methanol-to-Olefins (MTO) reaction over H-SAPO-34 catalysts. J Catal 264(1):77-87

20. Mei C et al (2008) Selective production of propylene from methanol: mesoporosity development in high silica HZSM-5. J Catal 258(1):243-249 